\title{
Street orientations: The first step towards a sustainable place
}

\author{
Saad Khudhair Mahmood Al-jumaili \\ Al- Nahrain University, College of Engineering, Architectural Department, Baghdad, Iraq
}

Email address:

aljumaily.saad@ymail.com (S. K. M. Al-jumaili)

\section{To cite this article:}

Saad Khudhair Mahmood Al-jumaili. Street Orientations: The First Step towards a Sustainable Place. American Journal of Environmental Protection. Vol. 3, No. 6, 2014, pp. 305-317. doi: 10.11648/j.ajep.20140306.12

\begin{abstract}
In recent times emerged a lot of interests that seek to achieve sustainability in all fields, including the buildings and their relationship to the streets, which requires the organization of the relationship according to the local climate characteristics of each city, there are cities characterized by a warm climate, dry and other cities Hot- wet or cold or desert. These characteristics, must have a clear impact on the urban planning and Urban design in order to create sustainable cities. Main streets planning geographical and directing style plays a big role in achieving sustainability of cities where lined and organized by public and private, commercial and service to recreational buildings that make up the urban landscape architecture, and is the ideal direction for these streets are the first step towards the sustainability of cities, and that the sustainability of cities is not a luxury intellectually but are needed actual and important step that must be observed by the planned urban designer. There is variation in the intensity of the main streets in the city of Baghdad use by the people, first; some of them are not encouraged to walk during the day time, secondly; others lacked environmental efficiency, because of the presence of sunlight annoying, third; the lack of environmental processors provide protection for people during the movement, and the lack of fit comfortably with the height of the buildings display those streets. So there was a need to assess this situation through the creation of a comparison between the ideal orientations and the current orientation of the main streets of Baghdad city as a model. Pol service Report (1982); To be the perfect orientations for buildings in hot dry areas is 350 East toward the South. In spite of the lack of reference to the ideal orientations to the streets directly, but he took it, that the main streets will inevitably be in the same orientations at an angle of 350 buildings any South- east being lined up on those streets. The research aims to verify the ideal orientations for a number of the main streets of the Baghdad city, which constitute the urban structure, and the results showed that all the samples that have been verified lacks ideal orientations. Find the perfect guidance recommends the adoption in the planning and design of future studies and to find the necessary solutions to fix the reality of the streets that are an essential step towards achieving sustainability of cities.
\end{abstract}

Keywords: Ideal Orientation, Street Orientation, Sustainable Place

\section{Introduction}

The quality of the places we live in has an impact on all aspects of life. How well they are designed will influence how safe we feel, how easy it is to walk round, whether we have shops, community facilities and schools nearby, whether our children have safe places to play. It will also affect whether there is good access to public transport and a good choice of homes in which to live. It is essential that the places we create and improve embody the principles of good urban design. Good urban design is essential to deliver places which are sustainable on all counts: places that create social, environmental and economic value. Ensuring that places are well designed should be a priority of everyone involved in shaping and maintaining the built environment. [1]

The city is consists of tangibles and Intangibles elements, the tangible elements consist of physical form, floors and various activities physical elements contribute to the powerful of the planning, architecture and urban design.

The floors surface represents, the surface links between the buildings and between external and internal spaces, at the same time it is the interval between the surface of these elements, in additions to that, the place for waiting, walking, and different activities.

Intangibles elements include habits, traditions, humanitarian activities, songs, rituals, symbols, popular 
costumes, folklore...etc. But are these elements or components sufficient to make the city or places vibrant and encourage people to use it constantly, without that meet ecological needs, comfortable environment in which they feel comfortable during human movement, sitting and waiting, certainly not be sufficient.

There are commercial and service shops operate with difficulty during the day, on the contrary, including the other side of the street, the man had difficulty and inconvenience while crossing from side to side, the streets seem sometimes free during daylight hours and crowded pm at the demise of the sun, there are shops owners waiting for the evening to work because of the natural heat of the sun.

How did this happened and how to treating it? How to achieve development, how to achieve sustainability broad form? The answer is the ideal orientation missing in the main streets, which represents the forms of the city.

The present time emerged the concept of sustainability, which has expanded to include the sustainability of cities in order to check the balance and take advantage of local resources and geographical characteristics for the production of environmentally sustainable cities, healthy and safe, comfortable and effective work throughout the day.

Emerged at the present time the concept of sustainability, which has expanded to include urban sustainability in order to achieve balance through the utilization of local resources and geographical characteristics, which requires reconsideration of the employed for the production of healthy, safe, comfortable and efficient urban environment working on throughout the day.

The current research focuses on the side of those local and geographical characteristics to achieve the sustainability of places, a public street directional proportion to the solar radiation received by all day period, which is considered the first step towards achieving sustainability of cities. Especially the main streets of Baghdad city that does not encourage people to walk or move and exercise daily activities as well as being non-stimulating and unhealthy as a result of people's inability to withstand harsh environmental conditions for long hours of the day, because of the heat and the lack of those streets to processors The ideal environmental research and orientations which aims to be verified.

\section{Sustainable Place}

A place which, through natural or man-made attributes, is able to foster conditions physically, functionally, culturally and institutionally that prolong and nurture life - generating forces for man. [2] The Habitat theory Postulates that 'aesthetic satisfaction' experienced in the contemplation of landscape, stems from the spontaneous of landscape features which, in their shapes, colours, spatial arrangements and other visible attributes, act as sign-stimuli indicative of environmental conditions favorable to survival, whether they really are favorable or not. This implies that man's relationship with environment satisfies functional biological needs and provides psychological comfort. [2] Concisely,
Habitat Theory is about the ability of a place to satisfy human biological and psychological needs. [2]

All cities are different and some offer their citizens more advantages than do others. A list of such advantages can be constructed by following Maslow's hierarchy of human needs (Maslow, 1954).

1 A 'good' city provides for all the physical needs of its citizens: a place to live and work, a reasonable income, education and training, transport and the possibility to communicate, access to services and facilities.

2 A 'good' city offers safety, security and protection, a visually and functionally ordered and controlled environment free of pollution, noise, accidents, crime.

3 A 'good' city offers, furthermore, a conducive social environment. It is a place where people have their roots and children have their friends; it enables the individual to be part of a community and provides the feeling of belonging to a place, to a territory.

4 A 'good' city has an appropriate image, a good reputation and prestige; it gives people a sense of confidence and strength, a status and dignity.

5 A 'good' city offers people a chance to be creative, to shape their personal space and to express themselves; it offers communities the chance to shape their districts and neighbourhoods according to their needs and aspirations.

6 And finally, a 'good' city is well designed, aesthetically pleasing, physically image able; A 'good' city is a place of culture and a work of art. [3]

For this, highlight the importance of knowing the impact of the following guidance to meet the humanitarian needs of the place before them and the streets that will have a significant impact in encouraging people to use them:

- Human Psychology Needs.

- Human Biological Needs.

- Aesthetics Satisfaction Needs.

\section{Benefits of Sustainable Place}

1 It Saves Money - More compact, durable and adaptable development, along with redevelopment in existing areas, will reduce the financial burden of building and maintaining additional public and private infrastructure.

2 It Creates a Stronger Economy - By reducing energy and infrastructure costs, creating more vibrant markets, expanding the pool of qualified workers and fostering innovation, we create a stronger, more stable and more resilient economy.

3 It Preserves and Enhances the Environment - By reducing emissions, managing storm water, preserving natural areas and conserving resources, we create healthier, more resilient and more attractive places to live.

4 It Fosters a Healthier Population - With more options for walking, biking and exercise, better access to healthy foods, and cleaner air and water, we will foster healthier lifestyles, reducing health care costs and stress on the 
health care system.

5 It Promotes Stable, Enduring Neighborhoods - By encouraging compact, mixed - use centers and corridors, a systems-based approach to planning and inclusive public decision-making, we help support thriving , attractive, enduring neighborhoods.

6 It Expands Access - By improving access to jobs, education and basic services, and providing quality, affordable housing in all parts of the region, we can improve the quality of life and also help build a stronger, more competitive economy.

7 It Provides More Choices — By encouraging more housing choices and transportation options, and fostering the development of convenient, affordable places for people to live, work and play, we enhance the livability and attractiveness of our communities.

8 It Ensures a Thriving Future -With enduring and adaptable communities, and an innovative, resilient economy, we will help ensure that the region will provide a high quality of life for our children and grandchildren. [4]

\section{Importance of Streets}

Currently the main streets in the cities considered, the available places to the general public to gain access to it and use it to meet the needs of the local community and visitors, it's supposed to be characterized by population housing density and mixed-use, in addition to the economic, cultural, social and recreational activities. These streets are considered as being of public buildings and private constitute a large urban mass compared with surrounding.

Streets are an important part of our cities and towns. They allow children to get to school and parents to get to work. They bring together neighbors and draw visitors to neighborhood stores. These streets ought to be designed for everyone - whether young or old, on foot or on bicycle, in a car or in a bus - but too often they are designed only for speeding cars or creeping traffic jams. [3]

\section{Benefits of Sustainable Streets}

Walking is the most ancient and universal form of travel. It is also an important form of exercise and recreation. Every personal trip involves walking, alone or in combination with taking public transit, driving, or cycling. The traditional concept of the street that "the way that meets the needs of wheel movement." This concept has changed and become street another job that distinguish it from being a road.

Streets are not just for movement, The quality of this public realm can improve our quality of life and increase our desire to spend time in these places.[1]

A pedestrian is a person moving from place to place either by foot or by using an assistive mobility device. Pedestrians include residents and visitors to the city of all ages and abilities. In order to travel safely, conveniently, directly, and comfortably, they require an urban environment and infrastructure designed to meet their travel needs.[6] A successful and sustainable local neighbourhood is a product of the distances people have to walk to access daily facilities, the presence of a sufficient range of such facilities to support their needs, and places and spaces where a variety of activities can take place.[1] Commercial activities play an important role in any vibrant community. As the commercial activities increase, there are more people involved with it, and resulting on active involvement of people in these areas. Large amount of retail spaces would also add up in making the area more popular to the people, increasing activities around these facilities.[7] This functions turned the street from the dynamic transitional space works as a conduit for the movement of cars and people primarily to dynamic space-to-resident-transitional, making it more versatile in their uses and to meet the needs of the local community.

The effects of orientation on changing street qualities influence on the solar envelope, there should be some mention of important temporal differences of streets themselves resulting from orientation.[8] Tree shade plays an important role in walkability analysis. Higher number of trees or greater tree shades creates a greener community, and changes the streetscape. Also, road side trees would makes pedestrian easier to walk. So, having lots of trees not only good for environment but also creates pleasing environment for pedestrians to walk on road From the road side trees point file the density map for tree shade is calculated.[7] The Congress for the New Urbanism recognizes that cities within the context of their surrounding regions are the social, cultural, and economic foundation of human civilization. they assert that the street network provides the setting for commerce and social interaction, and that construction, operation, and maintenance of the street network is primarily to serve people and society.

They propose the following principles to guide public policy, development practice, transportation planning and engineering, and urban design:

1 Street networks fulfill a basic need in human society. They connect people to each other and to destinations.

2 Sustainable street networks are magnets for business, light industry, jobs, and economic opportunities.

3 All people should be able to travel within their community in a safe, dignified and efficient manner.

4 Sustainable street network respects, protects and enhances the natural features and ecological systems of its urban environment.

5 The scale and orientation of streets in the network celebrate the unique local and regional characteristics of the natural and built environment.

6 Our most valued urban places are principally designed for the use and enjoyment of people on foot.

7 The street network is a foundation for the design and evolution of other transportation systems, including highways, rail, freight and air travel. [9]

But how We can exercise effective walking or access and use into the street if it is not comfortable from the environmental point of view, hence the importance of the 
street directing according ideal for routing to facilitate the access and use, and make it a street sustained year-round task, and also highlights the importance of public streets and corridors parallel walking her case study so as to change his job from street to the place, and also highlights the importance of responsiveness to the needs of the community, from the safety and comfort and make them attractive environments and not repulsive to people and be available to all and is used at all times and environmentally protected.Recent global interests emerged to achieving urban sustainability through a review and study of the current reality of the cities and to reconsider the legislation and laws to develop solutions and mechanisms to improve the reality of urban to those cities, and these cities, for example, the city of "Toronto" where "Toronto" conference dealt with in (2002) the importance of health, stimulating cities and streets on the exercise of walking to reduce the reliance on the use of wheels.

To providing a comfortable, healthy, safe and enjoyable environment pedestrian, and lead to increased use of public transport and reduce car use, to help to practice many of the social and economic activities and cultural events. To achieve these ideas and attempts to highlight the importance of the reform of urban buildings and streets overlooking directing it as a major problem in achieving urban sustainability and thus provide such environments, where most of them lacked the ideal guidance, which constitutes the basis for achieving sustainability.

The concept of smart growth streets includes the following principles:

1 Incorporate ecological, community, and mobility functions.

2 Protect and enhance environmental resources and processes throughout the street's life cycle.

3 Design for context sensitivity that contributes to the character of the natural and built environment of the immediate and wider surroundings.

4 Form highly connected networks of complete streets.

5 Help to create comfortable settings for walking, gathering, and lingering, especially in neighborhoods and shopping districts.
1. Design and manage with speeds and intersections appropriate to the context.

2. Complete streets, according to the National Complete Streets Coalition, are public rights-of-way that are safe and comfortable for all users, such as pedestrians, bicyclists, motorists, transit riders, and people of all ages and abilities, including children, older adults, and people with disabilities.[10]

\section{Solar Orientation}

Orientation is about the position of your site, and your home, in relation to the things around it including the street, neighbouring buildings and of course, the angle of the sun and the wind that will be used to heat and cool your home [11] The placing of a building in relation to the sun; depending on the geographical area, the building may be oriented to maximize the amount of heat gained from solar radiation during the coldest months, or it may be oriented to minimize the amount of heat gained in the warmest months. [12] Therefore, the streets and private - public buildings affected by geographic location, to be observed by urban planner- designer.

\section{Building Orientations}

The housing Technical standards and Codes of Practice Report of Iraq that have been developed by "Polservice" at 1982, Indicates that, "orientation of buildings in hot-dry zone contained within $35^{\circ}$ south-east is advisable, however $25^{0}$ south-east gives the best balance, building should be elongated on east-west axis. the optimal proportion being 1 : 1.3 ." and optimal orientation is $5^{0}$ south-east, the permissible limit extending to $10^{\circ}$ south-east in Hot-humid zone " [13] The building to provide mutual shading and minimum exposure. Enclosed compactly planned and inward looking buildings are most suitable; Patios and courtyard are highly recommended. for large buildings, high, cubical and massive forms are advantageous. figure (1)

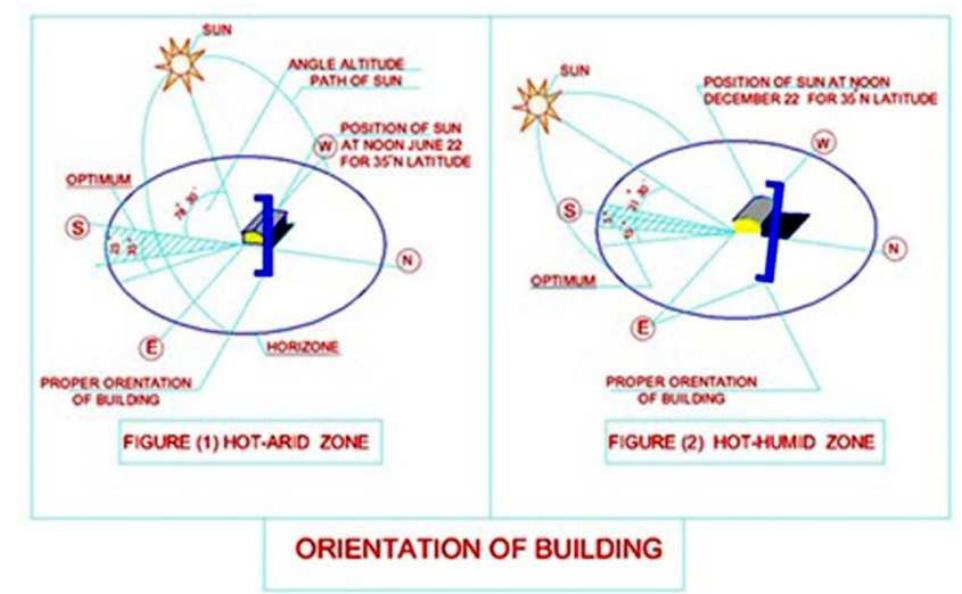

Figure (1) Guidance for building Orientations in A hot and hot-humid areas [13] 
By observing the figure above, that directing residential block toward $35^{0}$ south-east in the tropical dry, and it was the short rib Block perpendicular with it, but the assembling pattern of buildings in Iraq be attached with adjacent buildings on the one hand the longest side, not with the hand short rib. Therefore, the comfortable did not realized from the optimal orientations for buildings.

Thus, a strong link between the streets and residential blocks lined them regardless of whether or not to achieve comfort, and grew up a strong relationship between the building and the street, which overlooks it through the ideal direction for the two properties. Figure (2).

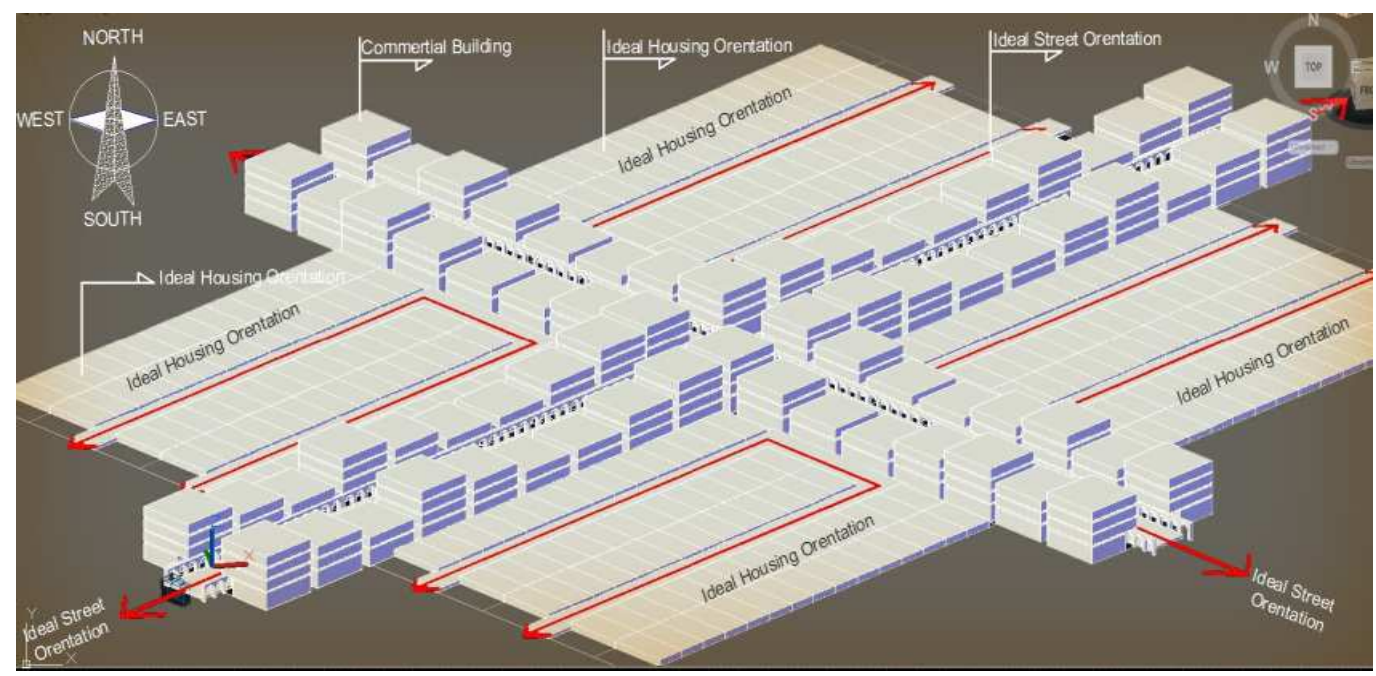

Figure (2) Ideal Streets and Buildings Orientations in A hot Zone

\section{Street Orientation}

Cities formed to allow a variety of people to come together to trade, to meet and to interact. Good urban design creates an environment that attracts a variety of users to interact with a variety of uses in a vibrant place that is successful socially, economically and environmentally. Good urban design is essential to deliver places which are sustainable on all counts: places that create social, environmental and economic value. Ensuring that places are well designed should be a priority of everyone involved in shaping and maintaining the built environment. [1] The main shopping streets and tourist areas of the city centre have to cope with the highest concentrations of all-day pedestrian activity. These areas need to be given priority in developing pedestrian priority measures, whether full pedestrianisation, footway widening or simply measures to enhance the attractiveness and safety of the pedestrian environment and encourage shoppers and visitors to enjoy the amenities of the city centre. [14] Sunlight penetration depends in large urban complexes to a large degree on the orientation of buildings, and design of streets, streets oriented from North to South to allow penetration of sunlight excessively in the middle of the day. While the penetration of sunlight in the street in the direction of East and West is happening in the morning and in the evening, when the low altitude of solar energy and solar radiation. and the penetration of sunlight on the upper part of the buildings is limited, a period most people to use those streets. In a hot-dry region the provision in the streets in summer is one of the major means for minimizing the heat stress of people walking in the street. Different orientations of the streets will result in different annual and diurnal patterns of the shading in the streets and along the sidewalks. [15] The solar envelope is a way to assure urban solar access for both energy and life quality. [16]

\section{Ideal Street Orientation}

Buildings and cities should be designed in response to local climate conditions. Considering topography, street layout, landscape, building massing and the choice of materials can help to avoid heat islands, modify summer peak temperatures and reduce energy loads on buildings. Urban design can significantly reduce the energy consumption of buildings through shelter and by providing opportunities for passive solar architecture, while also helping create a comfortable public realm. The combined effects of solar radiation, convection, thermal capacity, albedo (the extent to which an object reflects light) and wind can cause microclimates to differ by as much as $15^{\circ} \mathrm{C}$ in different parts of a city. [1] Streets make up a large part of people's experience of a place, they are the main location where people interact, they combine their function as a place with their role as part of a movement network for vehicles. [1] "Time sever" Books, pointed out that the directional street has a significant impact on the amount of solar energy falling and realized her shadow during daylight hours as well as their impact on the development during the hours of use of the land and the streets will be directed as follows:

\subsection{Ideal Street Orientation in Hot-Zone}

The best guide to the streets in the tropics must been towards in the axis (Northeast- Southwest) and the axis (Northwest - Southeast) to get the best insolation in the winter and less heat and better shading in the summer. [13] Figure (3) 


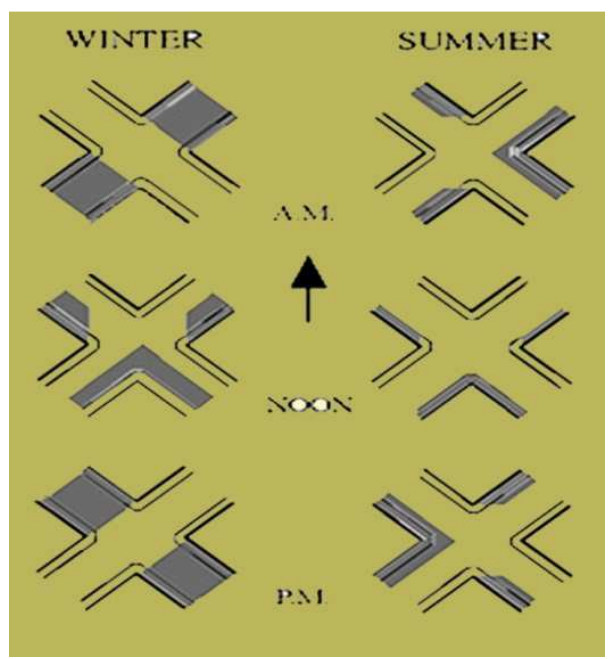

Figure (3) Orientation of streets in the hot dry [13]

\subsection{Ideal Street Orientation in Cold-Zone}

The best guide to the streets in the cold regions must been towards in the axis (North - south) and the axis direction (East - west) that it is investigating the best insolation in the winter and more heat and less shade in the summer. [8] Fig.(4)

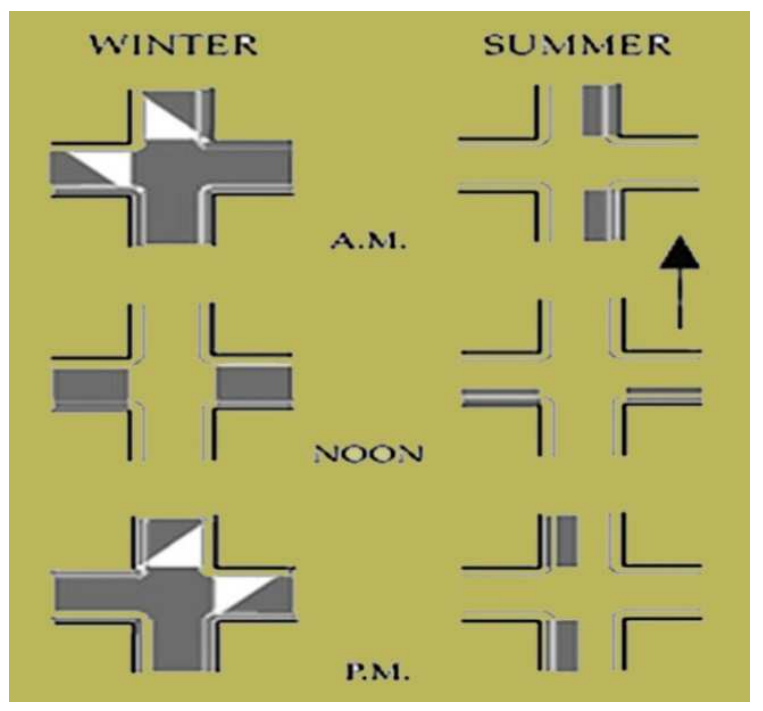

Figure (4) Orientation of streets in the cold [8]

\section{Methods}

By electing a number of important streets in the city of Baghdad as samples and a variety of single-use for the purpose of verification of their suitability for environmental standards and guidance especially ideal in warm areas. These streets are elected diverse business streets in their streets, a width and height of the surrounding buildings, in addition to the variation in the density provided by the varied uses of the land. However, the common property of these streets is being mean commercial streets by local people and those who dwell. Through the analysis of test results showing the absence of the streets ideal for samples elected, also shows that the main streets planning and orthogonal it don't take into account the importance of the perfect guidance and its impact on the sustainability of cities, which in turn will affect the cultural, economic and social development as a result of the incompetence of those streets and don't encourage people to use during the day. Adoption of horizontal extension policy and the weakness of population-housing density, the absence of the concept of space and poor containment processors will have to Put used by people with high efficiency, this research confirms the hypothesis.

Adoption of measurement and testing mechanism through the following:

1. Estimate (Ideal) for orientation, which is equal to $35^{0}$ Southeast and perpendicular streets with them.

2. Estimate (very comfortable) for orientation, which deviates $5^{0}$ for the perfect guidance from both sides up to $40^{\circ}$.

3. Estimate (comfortable) guidance which deviates by $10^{0}$ for the perfect guidance from both sides up to $45^{\circ}$.4Estimate (uncomfortable) Directive, which deviates by 200 for the perfect guidance from both sides up to $55^{\circ}$.

4. Estimate (very uncomfortable) Directive, which deviates by more than $20^{\circ}$ for the perfect guidance. Table(1)

Table (1) shows test results for the samples elected

\begin{tabular}{|c|c|c|c|c|c|c|c|}
\hline \multirow{2}{*}{ Currents Orientation } & \multicolumn{5}{|c|}{ Score } & \multirow{2}{*}{ Street Names } & \multirow{2}{*}{ No } \\
\hline & 5 & 4 & 3 & 2 & 1 & & \\
\hline $19^{0}$ Southeast & & * & & & & Haifa Street & 1 \\
\hline $46^{\circ}$ Southeast & & * & & & & Al-khlaffa Street & 2 \\
\hline $31^{0}$ Southeast & & & & $*$ & & Street 20/Al- Bayaa & 3 \\
\hline $51^{0}$ Southeast & $*$ & & & & & Imam Al-Muadham St. & 4 \\
\hline $4^{0}$ Southwest & * & & & & & 14 Ramadan Street & 5 \\
\hline $38^{0}$ Southeast & & & & $*$ & & Al- saadun Street & 6 \\
\hline $65^{\circ}$ Southeast & & & * & & & Karada Kharige Street & 7 \\
\hline $46^{\circ}$ Southeast & & $*$ & & & & Al-yarmouk ( 4 ) Street & 8 \\
\hline $19^{0}$ Southeast & & $*$ & & & & Al-Saydia Street & 9 \\
\hline $38^{0}$ Southeast & & & & $*$ & & 52 Street & 10 \\
\hline $33^{0}$ Southwest & & & & $*$ & & Qater al-Nada Street & 11 \\
\hline $17^{0}$ Southeast & & $*$ & & & & Al- Saha Street & 12 \\
\hline
\end{tabular}




\begin{tabular}{|c|c|c|c|c|c|c|c|}
\hline \multirow{2}{*}{ Currents Orientation } & \multicolumn{5}{|c|}{ Score } & \multirow{2}{*}{ Street Names } & \multirow{2}{*}{ No } \\
\hline & 5 & 4 & 3 & 2 & 1 & & \\
\hline $17^{0}$ Southeast & & $*$ & & & & Al-Amal Al-shaaby street & 13 \\
\hline $38^{0}$ Southeast & & & & $*$ & & Al-Rasheed Street & 14 \\
\hline $80^{\circ}$ Southwest & $*$ & & & & & New Baghdad Street & 15 \\
\hline $3^{0}$ Southwest & $*$ & & & & & Bab Al-qibla-Kadimia st. & 16 \\
\hline $42^{0}$ Southwest & & & $*$ & & & Al-flaah Street & 17 \\
\hline $58^{0}$ Southwest & $*$ & & & & & Al-jihad Street & 18 \\
\hline $43^{0}$ Southwest & & & * & & & Hay UR Street & 19 \\
\hline $22^{0}$ Southwest & $*$ & & & & & Al-Shirta Al-Rabiaa Str. & 20 \\
\hline $13^{0}$ Southeast & $*$ & & & & & Street 60/Doura & 21 \\
\hline $38^{0}$ Southeast & & & & $*$ & & Palestine Street & 22 \\
\hline
\end{tabular}

\section{The Results}

1. Test results showed that there is no ideal guide for the results of samples elected and the result was (zero).

2. Test results showed the presence of (6) the streets of elected samples guidance (Very comfortable).

3. Test results showed the presence of (3) elected from the streets of the samples with guidance (comfortable).

4. Test results showed the presence of (6) elected from the streets of the samples with guidance (uncomfortable).

5. Test results showed the presence of (7) Street of the samples with the elected steering (Very uncomfortable).

\section{Results and Discussion}

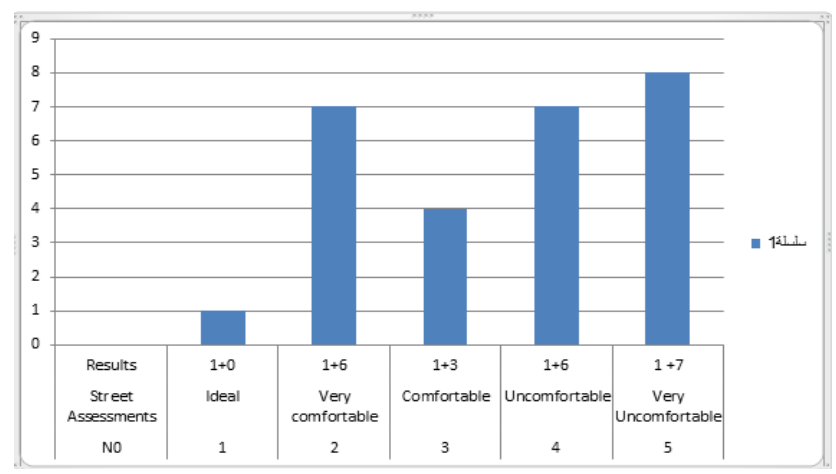

Figure (5) shows the relationship results for the samples elected

Through the analysis of test results showing the absence of the streets ideal for samples elected, also shows that the main streets planning and orthogonal it did not take into account the importance of the perfect guidance and its impact on the sustainability of the city of Baghdad, which in turn will effect on the cultural, economic and social development as a result of the incompetence of those streets and do not encourage people to use during the day. Keep in mind that not ideal orientation to the streets will contribute to the continued deterioration of the sustainability of the city, especially with the adoption of the horizontal extension policy and the weakness of population and housing density, absence of the concept of space and poor containment processors have, and this confirms the hypothesis of the research. The table number (2) shows test results for samples elected.
Table (2) shows the results for the samples elected

\begin{tabular}{cllc}
\hline No & Street Assessments & \multicolumn{2}{c}{ Results } \\
\hline 1 & Ideal & $1+0$ & 1 \\
2 & Very comfortable & $1+6$ & 7 \\
3 & Comfortable & $1+3$ & 4 \\
4 & Uncomfortable & $1+6$ & 7 \\
5 & Very Uncomfortable & $1+7$ & 8 \\
\hline
\end{tabular}

\section{Conclusions}

1. Inconsistency streets elected in line with the guidance ideal guidance of the local environment that caused the variation used by people efficiently .

2. Not ideal guidance to the streets and buildings into account when new streets and shops develop.

3. To check the environmental comfort and continuous use of it throughout the daylight hours, the streets are not especially developed to address those that lack the ideal guidance.

4. Domestic policies to study the reasons for non-commercial streets efficiency and not used during the period of the day before General No people all day period.

5. Failure to observe the ideal routing standards prepared by the company, "Paul Surf" in the seventies of the last century in the planning and design of construction projects that developed, making the weakest environmentally efficient.

6. Very weakness in Enclosure for most Streets.(see a appendix)

7. Very weakness in Trees.(see a appendix)

8. Very weakness in Arcades.(see a appendix)

\section{Recommendations}

1. Research recommends taking into account the ideal guidance to the streets in warm areas dry and wet and cold at the planning and design of urban environments, it represents one of the principles of sustainability.

2. Research recommends taking into account urban planning blocks tropical dry and wet and cold and put it in line with the ideal guidance for buildings and streets, 
and be the longest mass toward the ideal guidance, and put the smaller mass towards guidance is ideal.

3. Address the development of streets and urban blocks tropical dry and wet and cold to achieve urban sustainability by reviewing the heights under the principles of space containment as well as the use of appropriate trees that achieve protection for the users of those streets, and encourage the use of corridors, commercial and public buildings

4. Find reconsider the law recoil warm areas dry and wet and cold, which contributed to the increase of street width and sidewalks open and increase its exposure to direct sunlight is recommended.

5. Encouraging the establishment of corridors in thatched streets exposed to sunlight, to provide environmental protection for the movement.

6. Ensure environmental protection for the transition between the shops and residential sectors for pedestrians and cyclists, through the use of some design treatments such as corridors and landscaping or street directing appropriately ideal for routing.

7. Encourage people to exercise effective walking through the provision of safe, comfortable and interconnected corridors.

8. Encourage shopkeepers overlooking the main streets using some processors to provide environmental protection to be consistent with the design of the building.

9. Making a supportive local environments for walking and other activities, and this includes making homes located within walking distance of workplaces, shops, schools and ensuring access to recreational facilities, gardens and outdoor play.

\section{Appendix}

Table (3) Haifa Street Assessment

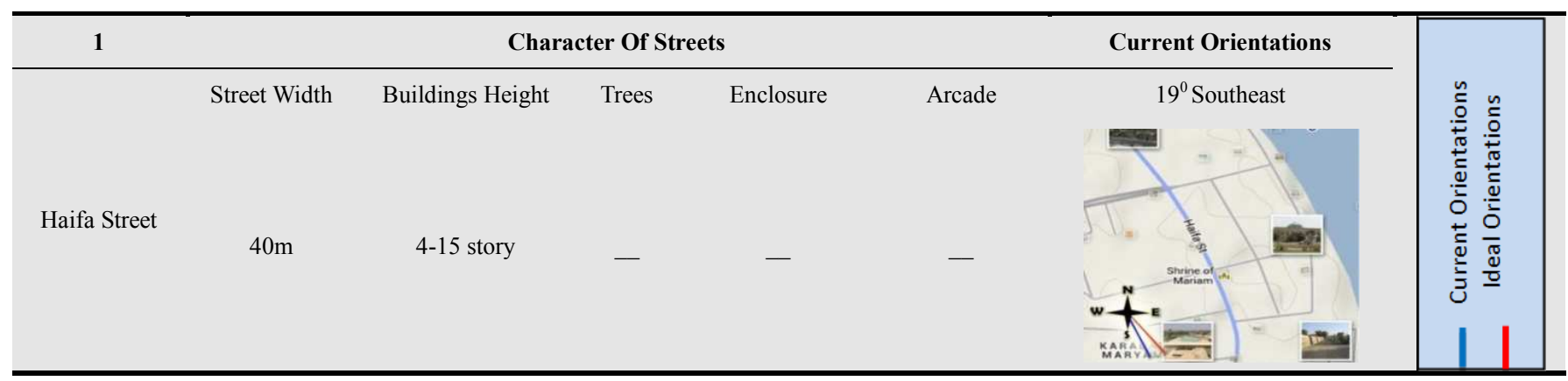

Table (4) Al-khulafa Street Assessment

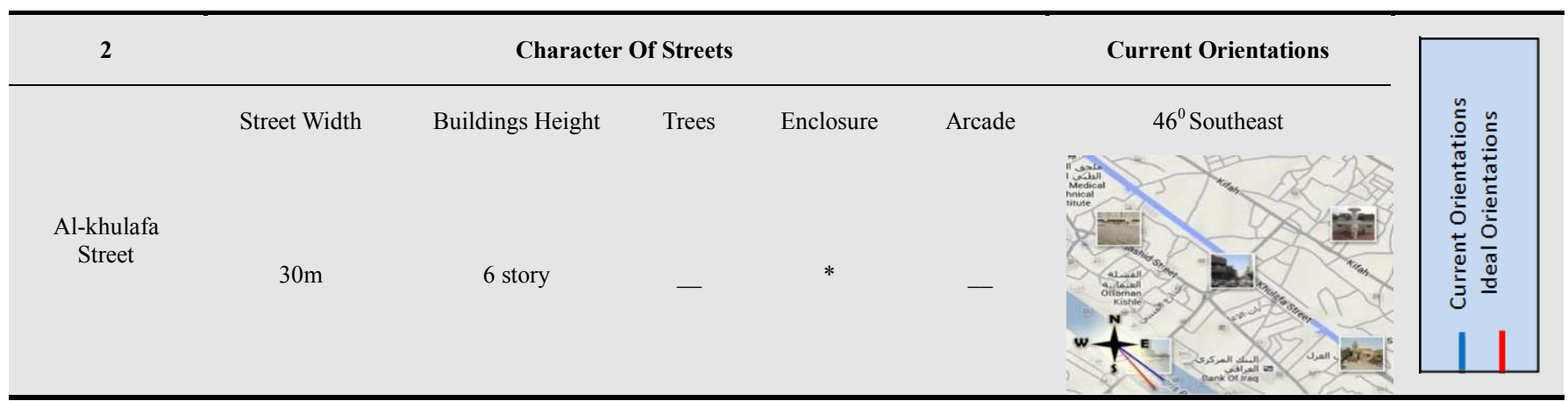

Table (5) Street 20 - Bayaa Assessment

\begin{tabular}{ccccccc}
\hline 3 & \multicolumn{3}{c}{ Character Of Streets } & & Current Orientations \\
\hline & Street Width & Buildings Height & Trees & Enclosure & Arcade \\
$\begin{array}{l}\text { Street } 20 \\
\text { Al-Bayaa }\end{array}$ & $20 \mathrm{~m}$ & 3 story & - & & & \\
\hline
\end{tabular}


Table (6) Imam Al-muadham St. Assessment

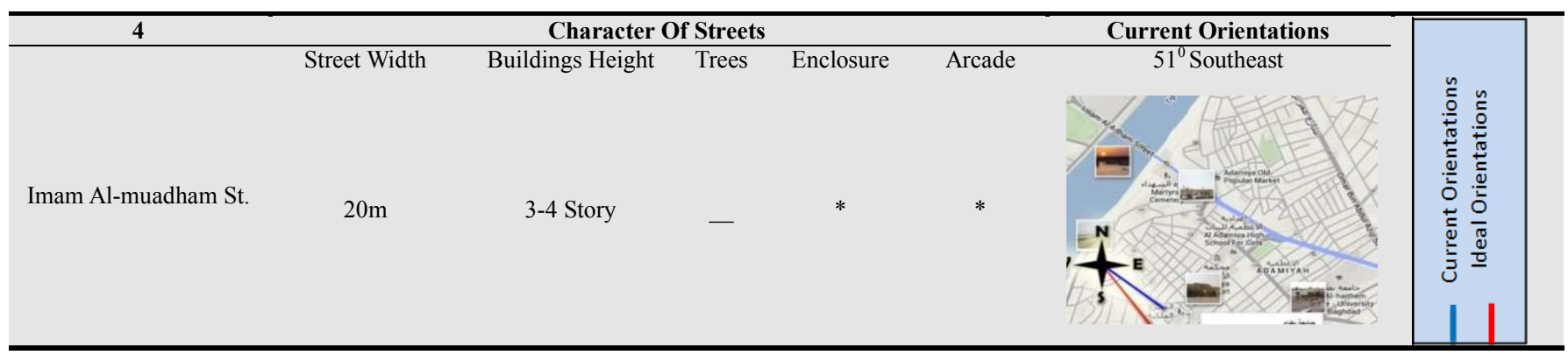

Table (7) 14 Ramadan Street Assessment

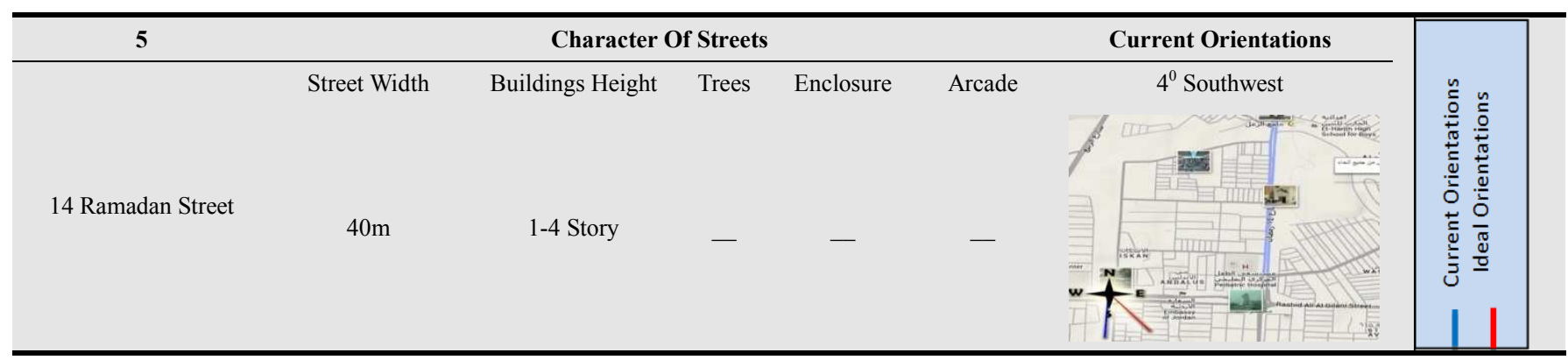

Table (8) Al-Saadoun Street Assessment

\begin{tabular}{|c|c|c|c|c|c|c|c|}
\hline 6 & \multicolumn{5}{|c|}{ Character Of Streets } & Current Orientations & \multirow{3}{*}{ 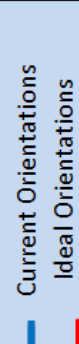 } \\
\hline & Street Width & Buildings Height & Trees & Enclosure & Arcade & $38^{0}$ Southeast & \\
\hline Al- Saadoun Street & $40 \mathrm{~m}$ & 6 Story & & & & & \\
\hline
\end{tabular}

Table (9) Karada Kharige Street Assessment

\begin{tabular}{|c|c|c|c|c|c|c|c|}
\hline 7 & \multicolumn{5}{|c|}{ Character Of Streets } & \multirow{3}{*}{$\begin{array}{c}\text { Current Orientations } \\
65^{0} \text { Southwest }\end{array}$} & \multirow{3}{*}{ 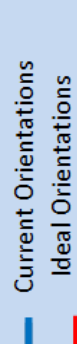 } \\
\hline & Street Width & Buildings Height & Trees & Enclosure & Arcade & & \\
\hline Karada Kharige St. & $30 \mathrm{~m}$ & 6 Story & - & $*$ & & & \\
\hline
\end{tabular}

Table (10) Al-Yarmook 4 Street Assessment

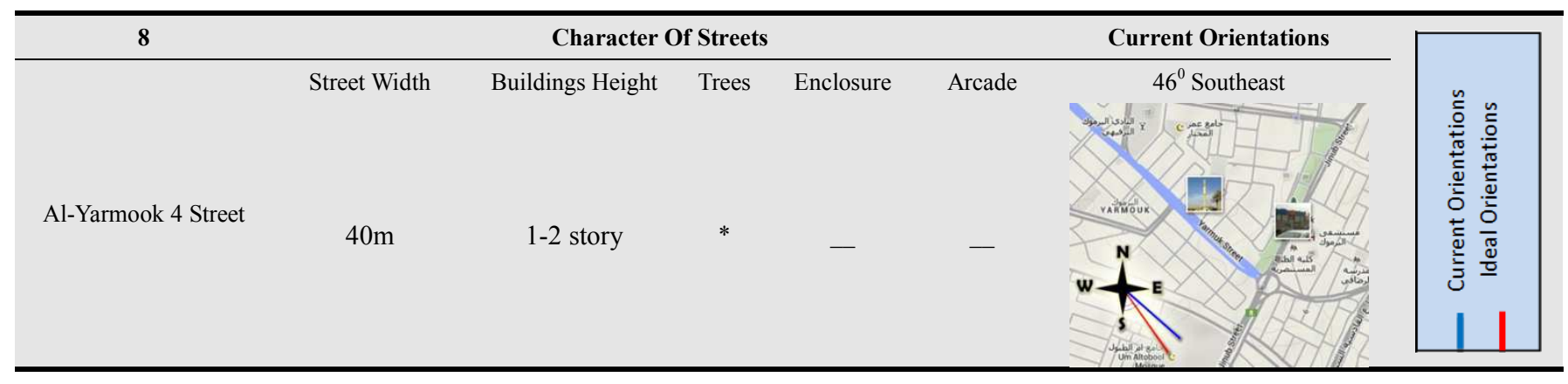


Table (11) Al- Saediya Street Assessment

\begin{tabular}{|c|c|c|c|c|c|c|c|}
\hline 9 & \multicolumn{4}{|c|}{ Character Of Streets } & & \multirow{2}{*}{$\begin{array}{c}\text { Current Orientations } \\
19^{0} \text { Southeast }\end{array}$} & \multirow{3}{*}{ 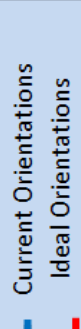 } \\
\hline & Street Width & Buildings Height & Trees & Enclosure & Arcade & & \\
\hline Al- Saediya Street & $40 \mathrm{~m}$ & 2-3 Story & & & - & & \\
\hline
\end{tabular}

Table (12) 52 Street Assessment

\begin{tabular}{|c|c|c|c|c|c|c|c|}
\hline 10 & \multicolumn{5}{|c|}{ Character Of Streets } & Current Orientations & \multirow{3}{*}{ 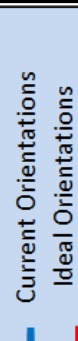 } \\
\hline & Street Width & Buildings Height & Trees & Enclosure & Arcade & $38^{0}$ Southeast & \\
\hline 52 Street & $30 \mathrm{~m}$ & 2-3 Story & & & & & \\
\hline
\end{tabular}

Table (13) Qater-Alnada Street Assessment

\begin{tabular}{|c|c|c|c|c|c|c|c|}
\hline 11 & \multicolumn{5}{|c|}{ Character Of Streets } & Current Orientations & \multirow{3}{*}{ 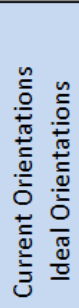 } \\
\hline & Street Width & Buildings Height & Trees & Enclosure & Arcade & $33^{0}$ Southwest & \\
\hline Qater Al-nada St. & $40 \mathrm{~m}$ & 3 Story & - & & & & \\
\hline
\end{tabular}

Table (14) Al-Sahaa Street Assessment

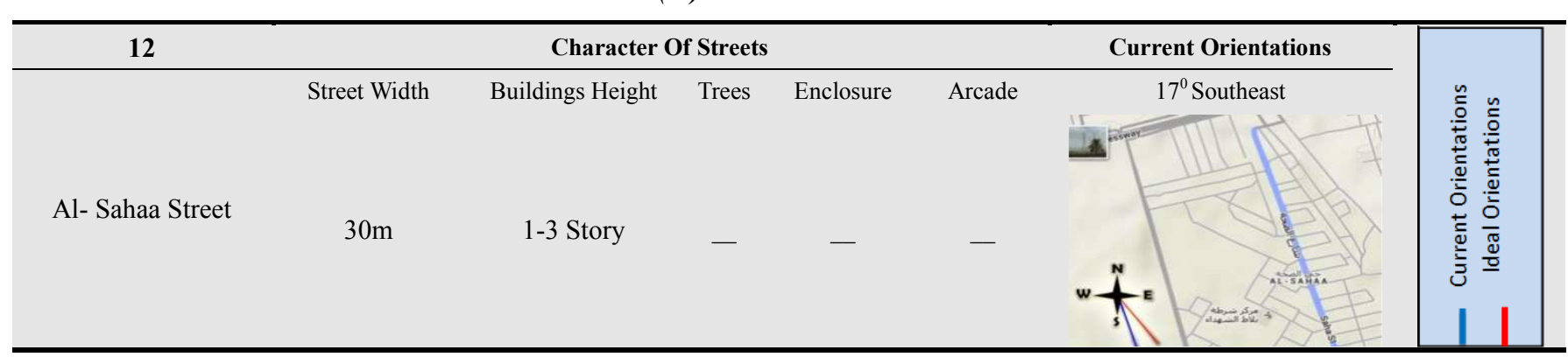

Table (15) Al-Amal Al-shaaby Street Assessment

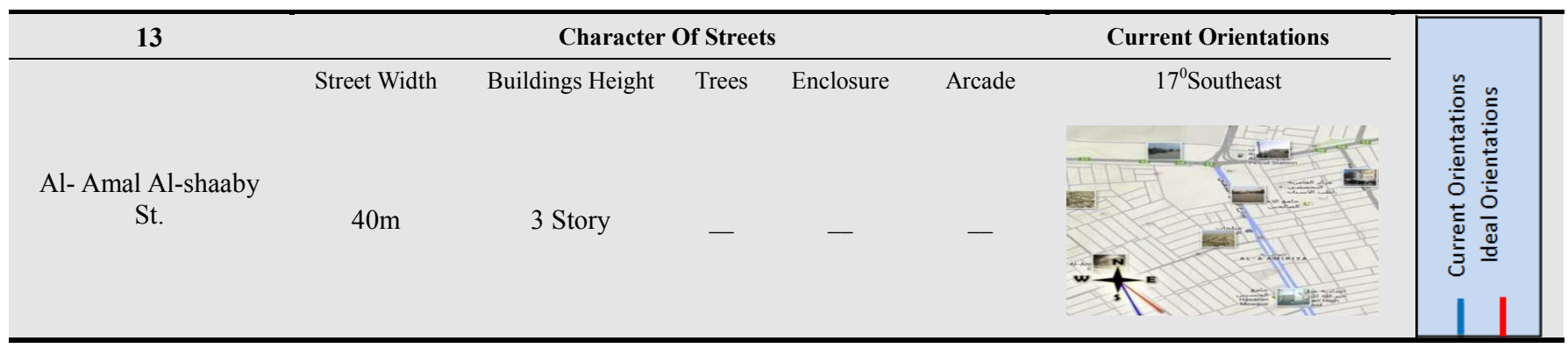


Table (16) Al-Rasheed Street Assessment

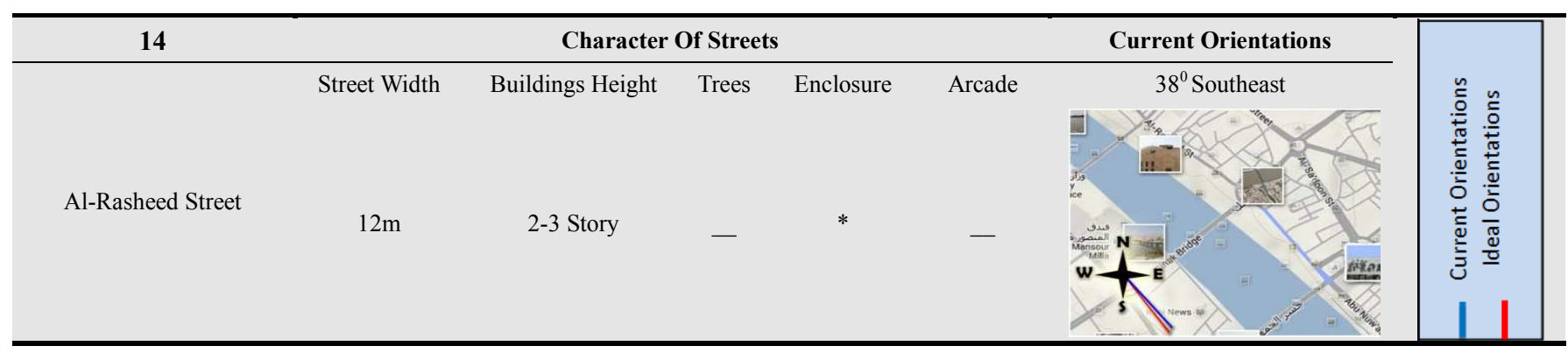

Table (17) New Baghdad Street Assessment

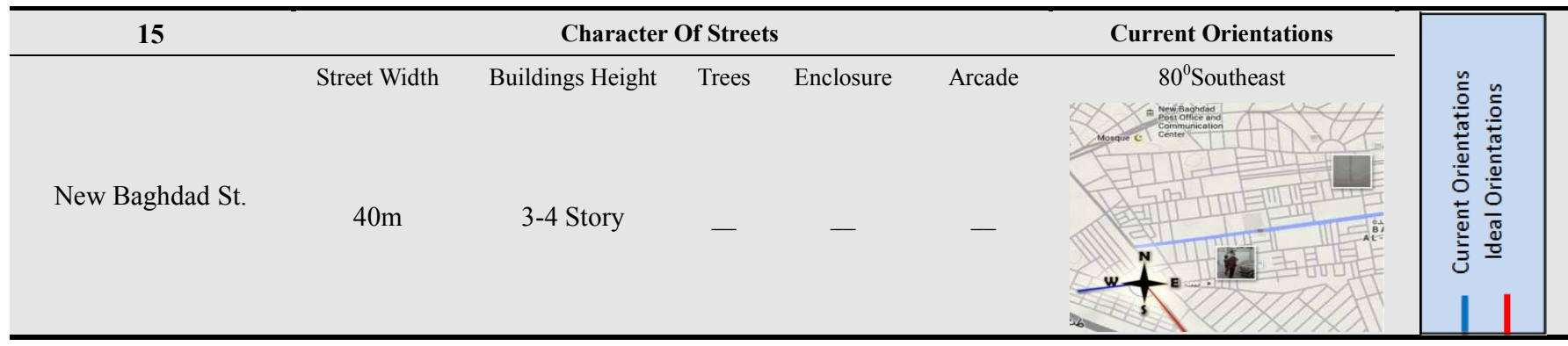

Table (18) Bab Al-qibla Street Assessment

\begin{tabular}{|c|c|c|c|c|c|c|c|}
\hline 16 & & Character & f Stree & & & Current Orientations & \multirow{3}{*}{ 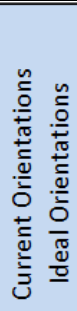 } \\
\hline \multirow[b]{2}{*}{ Bab Al-qibla Street } & Street Width & Buildings Height & Trees & Enclosure & Arcade & $3^{0}$ Southwest & \\
\hline & $15 \mathrm{~m}$ & 3-4 Story & & & & & \\
\hline
\end{tabular}

Table (19) Al-flellah Street Assessment

\begin{tabular}{|c|c|c|c|c|c|c|c|}
\hline 17 & \multicolumn{5}{|c|}{ Character Of Streets } & Current Orientations & \multirow{3}{*}{ 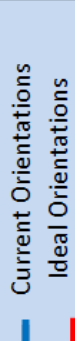 } \\
\hline & Street Width & Buildings Height & Trees & Enclosure & Arcade & $42^{0}$ Southwest & \\
\hline Al-flellah Street & $40 \mathrm{~m}$ & 3 Story & - & - & - & & \\
\hline
\end{tabular}

Table (20) Hay Al-jihad Street Assessment

\begin{tabular}{cccccc}
\hline 18 & \multicolumn{3}{c|}{ Character Of Streets } & \multicolumn{3}{c|}{ Current Orientations } \\
\hline Hay Al-jihad Street & Street Width & Buildings Height & Trees & Enclosure & Arcade \\
\hline
\end{tabular}


Table (21) UR Street Assessment

\begin{tabular}{|c|c|c|c|c|c|c|c|}
\hline 19 & & Character & f Stree & & & Current Orientations & \\
\hline & Street Width & Buildings Height & Trees & Enclosure & Arcade & $43^{0}$ Southwest & \\
\hline UR Street & $30 \mathrm{~m}$ & 2-3 Story & - & - & - & & 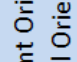 \\
\hline
\end{tabular}

Table (22) Al-Shurta Al-Rabiaa Street Assessment

\begin{tabular}{|c|c|c|c|c|c|c|c|}
\hline 20 & & Character & f Stree & & & Current Orientations & \multirow{3}{*}{ 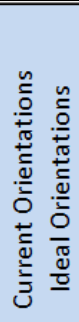 } \\
\hline \multirow[b]{2}{*}{ Al-Shurta Al-Rabiaa St. } & Street Width & Buildings Height & Trees & Enclosure & Arcade & $22^{0}$ Southwest & \\
\hline & $40 \mathrm{~m}$ & 2-3 Story & - & - & - & & \\
\hline
\end{tabular}

Table (23) Street 60/Doura Assessment

\begin{tabular}{|c|c|c|c|c|c|c|c|}
\hline 21 & \multicolumn{4}{|c|}{ Character Of Streets } & \multirow{2}{*}{\multicolumn{2}{|c|}{$\begin{array}{c}\text { Current Orientations } \\
13^{0} \text { Southeast }\end{array}$}} & \multirow{3}{*}{ 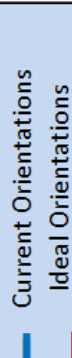 } \\
\hline & Street Width & Buildings Height & Trees & Enclosure & & & \\
\hline Street 60/Doura & $60 \mathrm{~m}$ & 2-3 Story & & & - & & \\
\hline
\end{tabular}

Table (24) Palestine Street Assessment

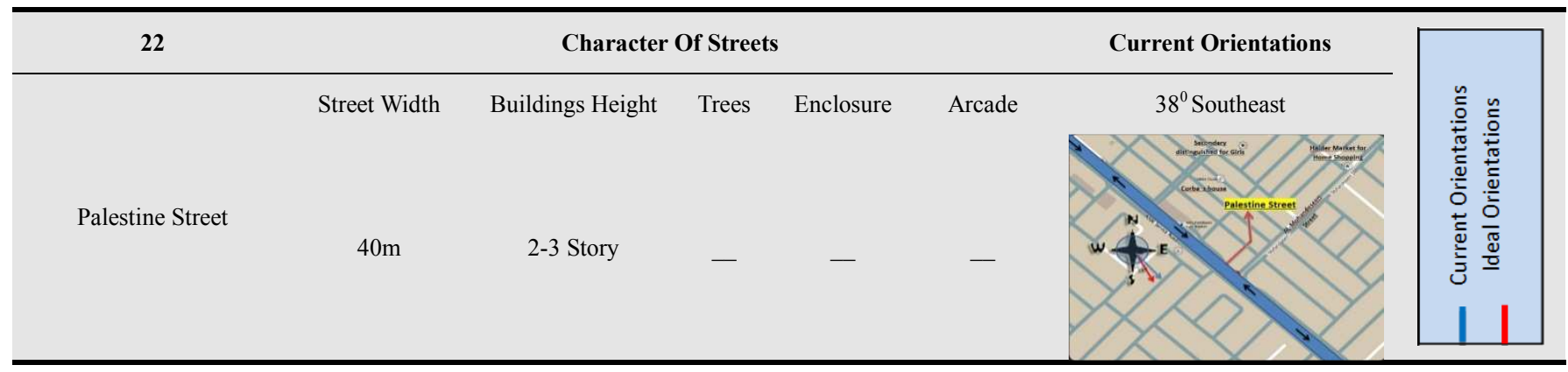

\section{References}

[1] Dvies, Llewelyn" Urban design Compendium 2" English partnerships, the housing Corporation, 2007. www.urbandesigncompendium.co.uk.

[2] Phillips; Christine;" Sustainable Place" A place of Sustainable Development; Published in Great Britain by WILEY-ACADEMY, 2003.

[3] Frey, Hildebrand "Designing the City Towards a more sustainable urban form" Routledge 29 West 35th Street, New York, NY 10001, 2005.

[4] "Creating Sustainable Places"; Kansas City Region Shares A Vision For Success; by Jeff Hirt, Barbara Hensley and Dean Katerndahl; 2003.www.mocities.com.

[5] National Complete Streets Coalition" Making Neighborhood Great Together, Smart Growth America; 2003. http://www.completestreets.org/complete-streets-fundamentals.

[6] Toronto Pedestrian2002, Charter, www.toronto. cat/transportation/walking/pdf/charter.pdf. 
[7] AGIS Based Walkability Analysis Submitted By: Prasanta Bhattarai, MUP Supervisor: Dr. Li Yin, Assistant Professor, Department of Urban \& Regional Planning; University at Buffalo August 2007.

[8] McGraw-Hill; "Time Saver -standard, Professional Publishing”, Two Penn Plaza, New York, NY. 2003.

[9] CNU Project for transportation reform; "Sustainable Street Network Principles", Congress for the new urbanism; copyright (C) 2012 published by Congress for the urbanism, the Marquette Building;140S. Dearborn Street, Suite 404, Chicago, I L606 03312. 551.7300. WWW. CNU.ORG, Congress for the new Urbanisms; 2012.

[10] Street Design: Part 2 - Sustainable Streets; by David J. Carlson, Ellen Greenberg, and Morgan Kanninen; Public Road, Vol. 74. No. 5; March/April 2011.
[11] www.sustainablemandurah.com.au.

[12] McGraw-Hill "Dictionary of Architecture and Construction". Copyright (C) 2003 by McGraw-Hill Companies, Inc.

[13] Polservice; "Housing Technical Standards and Codes of Practice" Report Two; printed by design office MIASTOPROJEKT-KRAKOW; Ministry of Housing and Construction-State Organization for housing, Baghdad, Iraq, 1982.

[14] Edinburgh City Local, Design Principles for New Development; Chapter 3.

[15] Givoni, Baruch; "Climate Considerations in Building and Urban Design"; copyright $\bigcirc 1998$ by John Wiley \&Sons, Inc. Canada,1998.

[16] Solar access-Wikipedia, the free encyclopediaen.wikipedia.org/wiki/Solar-access. 